\title{
Short-Term Effects of Topical Tafluprost on Retinal Blood Flow in Cats
}

\author{
Naohiro Izumi, Taiji Nagaoka, Eiichi Sato, Fumihiko Mori, Atsushi Takahashi, Kenji Sogawa, \\ and Akitoshi Yoshida
}

\begin{abstract}
Purpose: The aim of this study was to determine the short-term effects of topical tafluprost, a novel prostaglandin $\mathrm{F}_{2 \alpha}$ derivative, on feline retinal circulation.

Methods: Seventeen (17) adult cats were anesthetized with enflurane and mechanically ventilated. One (1) drop of tafluprost $(0.0015 \% ; n=8)$, latanoprost $(0.005 \% ; n=5)$, or control vehicle $(n=4)$ was instilled in 1 eye and the fellow eye was untreated. We measured the intraocular pressure (IOP), vessel diameter, and blood velocity simultaneously for $120 \mathrm{~min}$ in the large retinal arterioles and calculated the retinal blood flow (RBF) with a laser Doppler velocimetry system.

Results: Tafluprost $0.0015 \%$ significantly increased RBF (maximum change, $42.8 \pm 4.2 \%$ [mean \pm standard error of the mean; $P<0.01$ ) and blood velocity (maximum change, $24.1 \pm 3.3 \%$; $P<0.01$ ) for 120 min after instillation; there was no significant change in vessel diameter. Latanoprost $0.005 \%$ significantly increased $\mathrm{RBF}$ (maximum change, $31.7 \pm 3.4 \%$; $P<0.05$ ); there was no significant change in vessel diameter and blood velocity. There were no significant differences in the IOP reduction among the three groups.

Conclusions: We observed, for the first time, that topical tafluprost significantly increased RBF in cats, suggesting that dual-action tafluprost may be a beneficial antiglaucomatous agent for reducing IOP and increasing RBF.
\end{abstract}

\section{Introduction}

G LAUCOMA, WHICH IS THOUGHT TO BE a common optic neuropathy, often progresses despite well-controlled intraocular pressure (IOP). It is widely assumed that opticnerve damage results from not only mechanical compression caused by elevated IOP, but also from impaired ocular blood flow. ${ }^{1,2}$ Thus, the improvement in ocular blood flow is considered meaningful for glaucoma therapy. The $\beta$-blockers, betaxolol and nipradilol, and the carbonic anhydrase inhibitor, dorzolamide, have been reported to improve optic nerve head $(\mathrm{ONH})$ circulation in humans. ${ }^{3-5}$ The prostaglandin (PG) derivative, isopropyl unoprostone, was reported to increase $^{6-8}$ or not affect ${ }^{9}$ ocular blood flow in humans. In addition, recent studies have reported that latanoprost, a PGF $_{2 \alpha}$ analog, also was reported to increase ${ }^{7,10-20}$ or not affect ${ }^{21-27}$ ocular blood flow, including retinal blood flow (RBF), ${ }^{18}$ in various ocular regions and in various species.

Since tafluprost, a new $\mathrm{PGF}_{2 \alpha}$ derivative under development, is a highly selective and more potent prostanoid FP- receptor agonist, compared with latanoprost, it is expected to be highly effective in reducing IOP by enhancing the uveoscleral outflow. ${ }^{28-31}$ Because the effect of tafluprost on ocular circulation has never been evaluated, we investigated its effect on RBF in cats.

\section{Methods}

\section{Animal preparation}

Protocols describing the use of cats were approved by the Animal Care Committee of Asahikawa Medical College (Asahikawa, Japan) and were in accordance with the Association for Research in Vision and Ophthalmology Statement for the Use of Animals in Ophthalmic and Vision Research. Seventeen (17) adult cats of either sex (weight, 2.6-5.6 kg) were used in the study. With the animals in a closed box, anesthesia was induced with enflurane, oxygen, and nitrous oxide, followed by an intraperitoneal injection of atropine $(0.04 \mathrm{mg} / \mathrm{kg})$. A tracheostomy was performed, and the ani-

Department of Ophthalmology, Asahikawa Medical College, Asahikawa, Japan.

The authors have no proprietary interest in any aspect of this study. 
mals were mechanically ventilated with $1.5-2.0 \%$ enflurane and room air. Catheters were placed in the femoral arteries and veins. Pancuronium bromide $(0.1 \mathrm{mg} / \mathrm{kg} / \mathrm{h}$; Sankyo Pharmaceutical Co., Tokyo, Japan) was infused continuously. The animals were placed in the prone position, and the heads were fixed in a stereotaxic instrument. The arterial $\mathrm{pH}$, partial pressure of arterial carbon dioxide, partial pressure of arterial oxygen, and hematocrit were measured intermittently with a blood-gas analyzer (Chiba Corning Co., Tokyo, Japan). The arterial blood pressure and heart rate were monitored continuously. The rectal temperature was maintained between 37 and $38^{\circ} \mathrm{C}$ with a heated blanket.

The pupils were dilated with $0.5 \%$ tropicamide and $0.5 \%$ phenylephrine sulfate (Santen Pharmaceutical Co., Ltd., Osaka, Japan). We already had confirmed that phenylephrine does not alter the retinal circulation in cats. ${ }^{32,33}$ A 0 -diopter contact lens was placed on the cornea, which was protected with a drop of sodium hyaluronate (Healon; Pfizer Japan, Inc., Tokyo, Japan). A 26-gauge butterfly needle was inserted into the anterior chamber and connected to a pressure transducer to monitor the IOP.

\section{RBF measurement}

We measured the RBF by using a laser Doppler velocimetry system (Laser Blood Flowmeter model 100; Canon, Inc., Tokyo, Japan) that was customized for use in cats. The instrument, which is similar to a fundus camera, is designed to measure vessel diameter and blood velocity simultaneously in retinal vessels and to calculate the RBF. Diode (wavelength, $670 \mathrm{~nm}$ ) and helium-neon lasers (wavelength, $543 \mathrm{~nm}$ ) were used to measure the blood velocity and the vessel diameter, respectively. The diode laser was focused on the center of a vessel, and the helium-neon laser was positioned vertically to a vessel by direct visualization.

The principles of the laser Doppler velocimetry system have been described in detail elsewhere. ${ }^{32-36}$ Briefly, the blood velocity was measured by bidirectional laser Doppler velocimetry, which provides absolute measurements of the speed of the red blood cells (RBCs) flowing at discrete, selected sites in the retinal vessels, assuming Poiseuille's flow. ${ }^{37,38}$ The diode laser illuminates a retinal vessel at the same position. The Dopplershifted light scattered from the RBCs flowing in the retinal ves- sels is detected simultaneously in two directions and separated by a fixed angle. The signals from the two photomultiplier tube detectors undergo computer-controlled spectrum analysis and sequential measurement of the maximum speed $\left(\mathrm{V}_{\max }\right)$ at the center of the vessels. In the laser Doppler velocimetry system, each pair of spectra was recorded, and the $V_{\max }$ was calculated automatically every $5 \mathrm{msec}$ for $1 \mathrm{sec}$ during each measurement. The $\mathrm{V}_{\max }$ was defined as the averaged $\mathrm{V}_{\max }$ during one cardiac cycle. Measurement sites were generally between the first and second bifurcations.

The diameter of the retinal vessel was determined automatically by computer analysis of the signal produced by the image of the vessel. The vessel images were captured every $4 \mathrm{msec}$ for $60 \mathrm{msec}$ just before and after the blood-velocity measurement. Using microdensitometry, the captured images were analyzed to obtain the vessel diameter by using the half height of the transmittance profile to define the vessel edge. ${ }^{39}$ The value of the vessel diameter was defined as the average of the values determined at each time point.

The mean arterial blood pressure (MABP) was calculated as $1 / 3$ systolic arterial blood pressure $+2 / 3$ diastolic arterial blood pressure. The RBF was calculated from the formula:

$$
\mathrm{RBF}=\mathrm{S} \times \mathrm{V}_{\text {mean }}
$$

where $S$ is the cross-sectional area of the retinal artery at the laser Doppler measurement site, assuming a circular crosssection, and $V_{\text {mean }}$ is the mean blood velocity calculated as $\mathrm{V}_{\text {mean }}=\mathrm{V}_{\text {max }} / 2 .{ }^{40}$ The ocular perfusion pressure (OPP) was calculated as 2/3 MABP - IOP. ${ }^{41}$

\section{Application of ophthalmic solution and protocol}

Tafluprost $(0.0015 \%)$ and latanoprost $(0.005 \%)$ ophthalmic solution were provided by Santen Pharmaceutical Co., Ltd., and Pfizer Japan Inc., respectively. With a micropipette, 30 $\mu \mathrm{L}$ of tafluprost $(0.0015 \% ; \mathrm{n}=8)$, latanoprost $(0.005 \% ; \mathrm{n}=$ $5)$, or control vehicle $(n=4)$ was instilled into the right eyes in a masked manner. The contralateral eyes were untreated.

The RBF measurements started 15 min before the application of each drug; an average of five measurements at 1min intervals was defined as the baseline value before the instillation. After the instillation, measurements were per-

Table 1. Changes in Systemic and Ocular Parameters

\begin{tabular}{|c|c|c|c|c|c|c|}
\hline \multirow[b]{2}{*}{ Parameter } & \multicolumn{2}{|c|}{$\begin{array}{l}\text { Vehicle } \\
(\mathrm{n}=4)\end{array}$} & \multicolumn{2}{|c|}{$\begin{array}{l}\text { Tafluprost } 0.0015 \% \\
(\mathrm{n}=8)\end{array}$} & \multicolumn{2}{|c|}{$\begin{array}{l}\text { Latanoprost } 0.005 \% \\
(\mathrm{n}=5)\end{array}$} \\
\hline & Before & $120 \mathrm{~min}$ & Before & $120 \mathrm{~min}$ & Before & $120 \mathrm{~min}$ \\
\hline $\mathrm{pH}$ & $7.36 \pm 0.19$ & $7.37 \pm 0.20$ & $7.37 \pm 0.21$ & $7.35 \pm 0.18$ & $7.39 \pm 0.16$ & $7.38 \pm 0.23$ \\
\hline $\mathrm{PaCO}_{2}(\mathrm{mmHg})$ & $31.1 \pm 1.1$ & $31.6 \pm 0.9$ & $32.2 \pm 1.4$ & $31.6 \pm 1.3$ & $31.8 \pm 1.3$ & $30.8 \pm 1.2$ \\
\hline $\mathrm{PaO}_{2}(\mathrm{mmHg})$ & $109.6 \pm 3.6$ & $112.0 \pm 4.4$ & $110.3 \pm 3.0$ & $113.6 \pm 2.7$ & $102.0 \pm 3.4$ & $104.3 \pm 4.1$ \\
\hline Hematocrit (\%) & $31.0 \pm 1.1$ & $30.3 \pm 1.4$ & $31.9 \pm 1.6$ & $32.0 \pm 2.0$ & $29.9 \pm 1.7$ & $30.2 \pm 2.2$ \\
\hline MABP (mmHg) & $95.8 \pm 3.2$ & $91.1 \pm 3.6$ & $86.6 \pm 3.5$ & $83.2 \pm 3.0$ & $93.3 \pm 3.0$ & $92.5 \pm 2.7$ \\
\hline $\mathrm{IOP}(\mathrm{mmHg})$ & $13.3 \pm 1.3$ & $9.0 \pm 1.5^{*}$ & $15.6 \pm 1.9$ & $12.1 \pm 1.6^{*}$ & $17.7 \pm 1.1$ & $13.9 \pm 1.0^{*}$ \\
\hline $\mathrm{OPP}(\mathrm{mmHg})$ & $50.5 \pm 2.5$ & $51.7 \pm 3.1$ & $42.1 \pm 2.7$ & $43.4 \pm 2.5$ & $44.5 \pm 2.5$ & $47.8 \pm 2.3^{*}$ \\
\hline HR (beats/min) & $150.7 \pm 7.8$ & $145.7 \pm 8.0$ & $141.4 \pm 9.4$ & $145.5 \pm 9.9$ & $139.5 \pm 8.1$ & $144.2 \pm 6.9$ \\
\hline
\end{tabular}

$\mathrm{PaCO}_{2}$, partial pressure of arterial carbon dioxide; $\mathrm{PaO}_{2}$, partial pressure of arterial oxygen; MABP, mean arterial blood pressure; $\mathrm{HR}$, heart rate; Before, before instillation; $120 \mathrm{~min}, 120$ minutes after instillation.

Note. Data are expressed as the means \pm standard error.

${ }^{*} P<0.05$ versus values before instillation by a paired Student $t$-test. 
formed every $10 \mathrm{~min}$ for $120 \mathrm{~min}$. At each time point, three successive measurements were taken, and the average of the three measurements was recorded.

\section{Statistical analysis}

All data are expressed as the mean \pm standard error of the mean. For statistical analysis, we used one-way analysis of variance (ANOVA), followed by post-hoc comparison with the Dunnett procedure. Differences between the means in systemic parameters before and $120 \mathrm{~min}$ after instillation were assessed with the Student paired $t$-test. In all cases, $P<$ 0.05 was considered significant.

\section{Results}

There were no significant differences in the arterial $\mathrm{pH}$, the partial pressure of arterial oxygen, the partial pressure of arterial carbon dioxide, the hematocrit, and the mean heart rate between the before and after instillations of tafluprost, its vehicle, and latanoprost (Table 1). There was no significant change in MABP during the measurements.

One hundred twenty (120) min after the instillation of tafluprost $0.0015 \%$, the vessel diameter, blood velocity, and $\mathrm{RBF}$ increased by $3.5 \pm 2.1 \%$ (from $90.1 \pm 2.3$ to $93.2 \pm 2.3$ $\mu \mathrm{m} ; P>0.05$, compared with the value in the vehicle group at the same time point), $12.2 \pm 3.0 \%$ (from $16.0 \pm 1.5$ to $17.9 \pm 1.5 \mathrm{~mm} / \mathrm{sec} ; P=0.042$ ), and $18.1 \pm 3.6 \%$ (from $3.0 \pm$ 0.8 to $3.5 \pm 0.7 \mu \mathrm{L} / \mathrm{min} ; P=0.017$ ), respectively (Fig. 1 ). The vessel diameter tended to increase only slightly during the measurement. The blood velocity increased to a maximum level $40 \mathrm{~min}$ after the instillation of tafluprost $0.0015 \%$, and that level was maintained until $120 \mathrm{~min}$ after instillation. The RBF reached a maximum level $50 \mathrm{~min}$ after instillation and then decreased slightly, but the increased level was maintained up to $20 \%$ until $120 \mathrm{~min}$ after instillation.

The instillation of latanoprost $0.005 \%$ resulted in increased vessel diameter, blood velocity, and RBF by $8.1 \pm 3.2 \%$ (from $101.9 \pm 3.6$ to $110.5 \pm 4.4 \mu \mathrm{m} ; P>0.05$, compared with the value in the vehicle group at the same time point), $3.4 \pm 3.1 \%$ (from $20.2 \pm 2.4$ to $20.7 \pm 2.3 \mathrm{~mm} / \mathrm{sec} ; P>0.05$ ), and $18.5 \pm$ $3.5 \%$ (from $5.1 \pm 1.5$ to $5.9 \pm 1.5 \mu \mathrm{L} / \mathrm{min} ; P=0.049$ ), respectively. The vessel diameter and blood velocity tended to increase slightly, but not significantly, during latanoprost treatment. The elevated RBF showed the maximum response $90 \mathrm{~min}$ after the instillation of latanoprost.

The incremental changes in velocity and RBF in the tafluprost $0.0015 \%$ group tended to be higher than those of the latanoprost $0.005 \%$ group at most measurement points but did not reach significance. In addition, tafluprost seems to cause an increase in the RBF faster than latanoprost (Fig. 1). Indeed, the group-averaged values of the mean times in which the maximum RBF changes were observed in the tafluprost $0.0015 \%$ and latanoprost $0.005 \%$ groups were $62.5 \pm 5.6$ and $82.0 \pm 3.9 \mathrm{~min}$, respectively.

Figure 2 shows the tafluprost $0.0015 \%$, its vehicle, and the latanoprost $0.005 \%$ group averages of the maximum changes in retinal circulatory parameters (e.g., diameter, velocity, and $\mathrm{RBF})$. Because there were some differences in the time course of the response to the drug in each cat, we defined as the maximum change that observed after instillation from the baseline value to prevent underestimation of the degree of
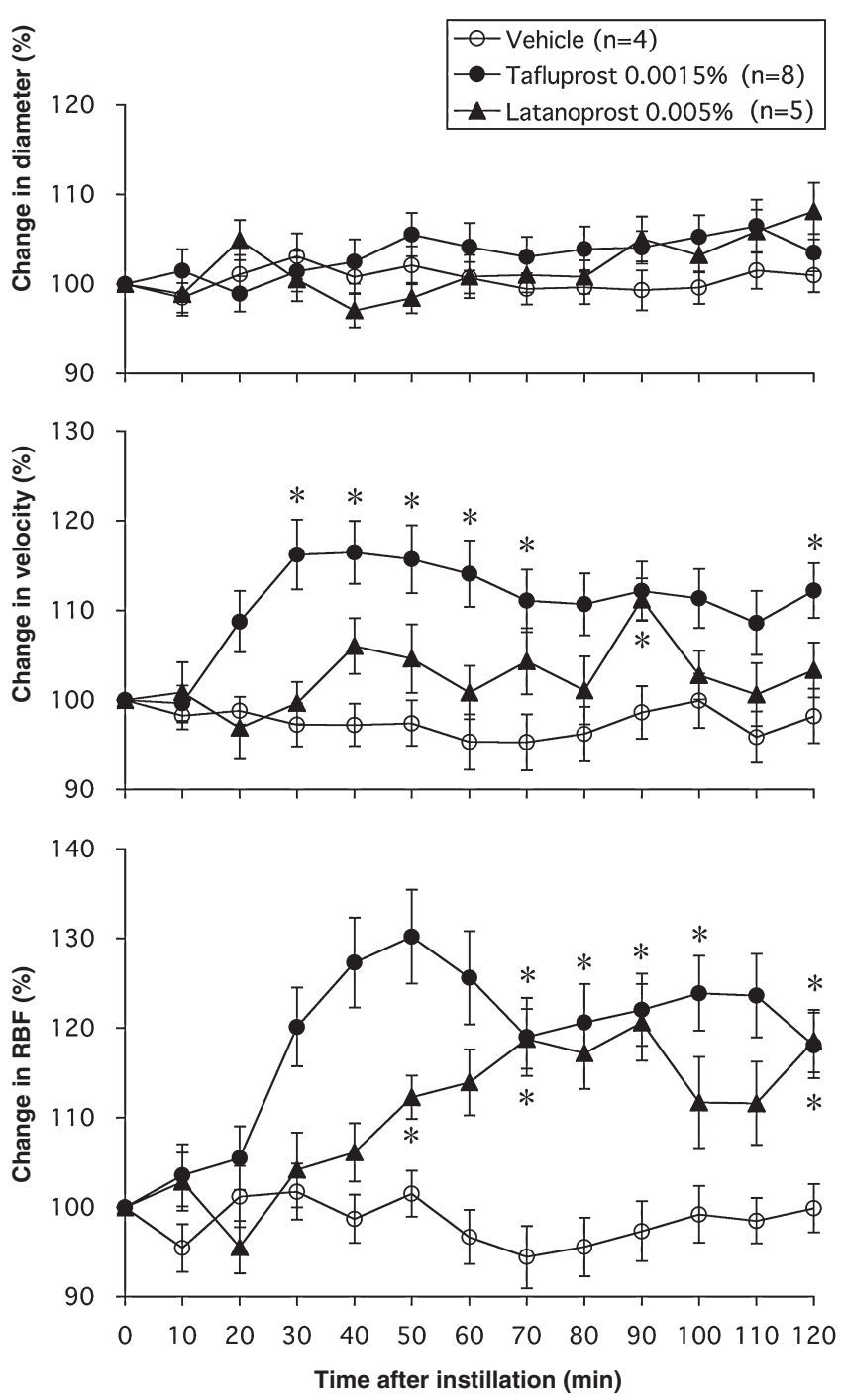

FIG. 1. Time course of the changes in retinal circulation after topical instillation of tafluprost $0.0015 \%$, its vehicle, and latanoprost $0.005 \%$. Data are presented as the mean \pm the standard error of the mean. Significant differences, compared with the vehicle at each time point, are indicated $\left({ }^{*} P<0.05\right)$ by one-way analysis of variance, followed by Dunnett's procedure.

the response. The maximum changes in the blood velocity in the tafluprost $0.0015 \%$ and latanoprost $0.005 \%$ groups were $24.1 \pm 3.3(P=0.007$, compared with the value in the vehicle group) and $16.6 \pm 3.2 \%(P>0.05)$, and the maximum changes in the RBF were $42.8 \pm 4.2(P=0.002)$ and $31.7 \pm$ $3.4 \%(P=0.040)$, respectively.

There was no significant difference in IOP values before instillation among the three groups. The IOP values decreased and the ocular perfusion pressure (OPP) values increased gradually during the $120 \mathrm{~min}$ after instillation in all groups, compared with the pretreatment values (Table 1). There were no significant differences in the IOP-lowering effect between tafluprost $0.0015 \%$ or latanoprost $0.005 \%$ and the control group throughout the evaluation. There was a significant increase in OPP only in the latanoprost $0.005 \%$ group. 


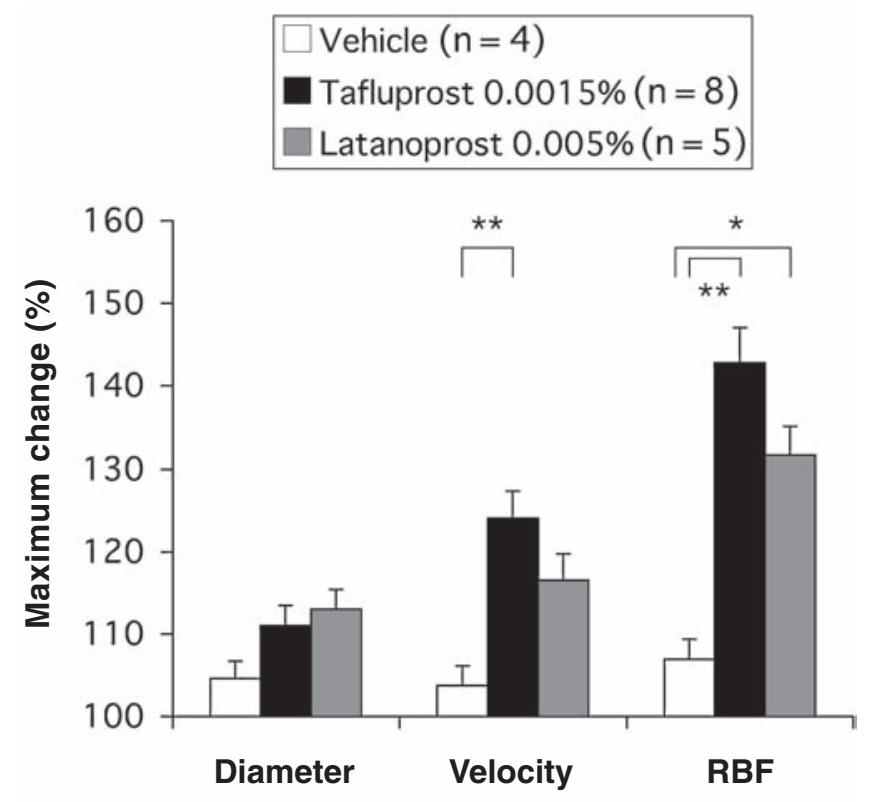

FIG. 2. Effects of tafluprost $0.0015 \%$, its vehicle, and latanoprost $0.005 \%$ in retinal circulation. Data are presented as the mean \pm the standard error of the mean. Significant differences, compared with the vehicle at each time point, are indicated $\left({ }^{*} P<0.05,{ }^{* *} P<0.01\right)$ by one-way analysis of variance, followed by Dunnett's procedure.

\section{Discussion}

We observed that one instillation of 1 drop of tafluprost $0.0015 \%$ increased RBF and blood velocity during $120 \mathrm{~min}$ after instillation, and that there were significant differences compared with the control group. With latanoprost $0.005 \%$, the changes in the parameters of the retinal circulation tended to be slightly smaller than the changes observed with tafluprost $0.0015 \%$. The increased RBF was caused mainly by the increased blood velocity at the measurement site, because the vessel diameter did not change substantially. Therefore, the observed increase in blood velocity might reflect a dilation of the downstream vessels. Taken together, we speculated that retinal microvessels located more peripherally than the points measured in this study might be dilated. Sponsel et al. reported that latanoprost increased the midperipheral retinal capillary microcirculation in humans, as measured by scanning laser Doppler flowmetry, ${ }^{18}$ which is consistent with our results.

Liu et al. reported that topical latanoprost increased the pulsatile ocular blood flow (POBF) in patients with normaltension glaucoma. However, the increase in the POBF might be caused by an increase in OPP caused by the reduction of IOP, because the changes in POBF no longer reached statistical significance after adjusting for the IOP. ${ }^{14}$ The OPP increased significantly in the latanoprost group but did not change in the tafluprost group (Table 1). Because there is a mechanism that autoregulates the RBF, the change in OPP observed in the latanoprost group seemed to have little effect on the increase in RBF.

The current results suggested that tafluprost might be more effective than latanoprost in increasing the RBF (Fig. 2). Sjoquist et al. reported that $30 \mathrm{~min}$ after topical applica- tion, the concentration of latanoprost was approximately $10^{-8} \mathrm{M}$ in the retina and choroid in Cynomolgus monkeys. ${ }^{42}$ Stjernschantz et al. reported that high doses of latanoprost tended to cause incremental changes in RBF in monkeys, but there were no significant changes. ${ }^{27}$ The affinity for the prostanoid FP-receptor of tafluprost acid was reported to be 12 times that of latanoprost and 1700 times that of isopropyl unoprostone. $^{30}$ Regarding the molecular structure, latanoprost has the hydroxyl group at position 15, which is reported to be dehydrogenated and inactivated by $\mathrm{NADP}^{+}$dependent 15-hydroxyprostaglandin dehydrogenase. ${ }^{43}$ On the other hand, tafluprost is a 15,15-difluoro $\mathrm{PGF}_{2 \alpha}$ derivative, which is not affected by this enzyme and more stable in vivo, compared with latanoprost. Therefore, these results suggested that the increased RBF resulting from the instillation of tafluprost might be related to the high affinity of tafluprost to the FP-receptors and the drug's structural characteristics.

Certain PGs, such as $\mathrm{PGI}_{2}$ and $\mathrm{PGE}_{2}$, usually act as vasodilators in many species. ${ }^{44}$ However, $\mathrm{PGF}_{2 \alpha}$ may exert different actions on blood vessels, depending on the species and tissues. ${ }^{27}$ Ishikawa et al. reported that latanoprost caused endothelium-independent vasodilation in isolated ciliary arteries in rabbits. ${ }^{45}$ Ishii et al. ${ }^{12,13}$ reported that latanoprost increased the circulation of the optic nerve head tissue in monkeys, rabbits, and humans and speculated that $\mathrm{PGF}_{2 \alpha}$ caused vasodilation through the $\mathrm{PGI}_{2}$ released from the subendothelial tissue, since the intravenous injection of indomethacin prevented an increase in the circulation of the optic nerve head in animals. Indeed, $\mathrm{PGF}_{2 \alpha}$ exerts vasodilatory effects through $\mathrm{PGI}_{2}$ in canine uterine arteries. ${ }^{46} \mathrm{Re}$ garding differences among species, Stjernschantz et al. reported that $\mathrm{PGF}_{2 \alpha}$ had more extensive microvascular effects in rabbits and cats, compared with primate eyes, such as in monkeys. ${ }^{27}$ Although we did not examine the effect of PGreceptor blockers in the current study, the increased RBF caused by tafluprost might result from the release of PGs. Further study using PG-receptor antagonists is needed to reveal the mechanism of the vasodilatory effect of tafluprost.

The retinal construction and circulation in cats are similar to those in humans, compared with small animals, such as rats. However, the microvasculatory effects of $\mathrm{PGF}_{2 \alpha}$ in cats are reported to be stronger than those in primate animals. ${ }^{27}$ Moreover, the degree of vascular reaction between cats and humans does not seem to be similar after the instillation of the same amount of solution, because the ocular volumes differ. Therefore, the change in RBF in humans may differ, or be attenuated, compared with those in cats.

Many studies have reported that PG analogs, especially isopropyl unoprostone and latanoprost, increase the ocular blood flow in various species. ${ }^{6-8,10-20}$ In the current study, we compared the vasodilatory effects of latanoprost with those of tafluprost. Although the mechanism is not fully understood, it has been reported that latanoprost increased $^{7,10-20}$ or did not affect ${ }^{21-27}$ the ocular blood flow. The current results that latanoprost increased RBF (Fig. 2) seem consistent with those results.

In the current study, the IOP decreased gradually during $120 \mathrm{~min}$ after instillation in all groups, although there were no significant differences in the decrease in IOP among the groups. It is well known that enflurane has substantial IOPlowing properties. ${ }^{47,48}$ Nakajima et al. reported that topical 
tafluprost did not change the IOP up to $2 \mathrm{~h}$ after instillation but reduced the IOP significantly $4 \mathrm{~h}$ after instillation in monkeys. ${ }^{28}$ These results suggest that the apparent effect of topical tafluprost on IOP reduction might take longer, compared with the effect on the retinal circulation. In addition, the effect of $\mathrm{PGF}_{2 \alpha}$ on IOP reduction was reported to be weak in healthy cats. ${ }^{49}$ Taken together, we speculated that the IOP reduction had little effect on the retinal circulatory response to topical tafluprost in healthy cats.

\section{Conclusions}

In conclusion, our findings showed, for the first time, that topical tafluprost increased the RBF in cats. Although these results cannot be extrapolated directly to humans and the mechanism needs to be clarified, this result is noteworthy and may be beneficial regarding the effect of antiglaucomatous agents on the ocular circulation.

\section{References}

1. Schumann, J., Orgul, S., Gugleta, K., et al. Interocular difference in progression of glaucoma correlates with interocular differences in retrobulbar circulation. Am. J. Ophthalmol. 129:728-733, 2000.

2. Yamazaki, Y., and Drance, S.M. The relationship between progression of visual field defects and retrobulbar circulation in patients with glaucoma. Am. J. Ophthalmol. 124:287-295, 1997.

3. Tamaki, Y., Araie, M., Tomita, K., et al. Effects of topical adrenergic agents on tissue circulation in rabbit and human optic nerve head evaluated with laser speckle tissue circulation analyzer. Surv. Ophthalmol. 42(Suppl 1):S52-S63, 1997.

4. Tamaki, Y., Araie, M., Tomita, K., et al. Effect of topical betaxolol on tissue circulation in the human optic nerve head. J. Ocul. Pharmacol. Ther. 15:313-321, 1999.

5. Fuchsjager-Mayrl, G., Wally, B., Rainer, G., et al. Effect of dorzolamide and timolol on ocular blood flow in patients with primary open-angle glaucoma and ocular hypertension. Br. J. Ophthalmol. 89:1293-1297, 2005.

6. Makimoto, Y., Sugiyama, T., Kojima, S., et al. Long-term effect of topically applied isopropyl unoprostone on microcirculation in the human ocular fundus. Jpn. J. Ophthalmol. 46:31-35, 2002.

7. Sponsel, W.E., Paris, G., Trigo, Y., et al. Comparative effects of latanoprost (Xalatan) and unoprostone (Rescula) in patients with open-angle glaucoma and suspected glaucoma. Am. J. Ophthalmol. 134:552-559, 2002.

8. Tamaki, Y., Araie, M., Tomita, K., et al. Effect of topical unoprostone on circulation of human optic nerve head and retina. J. Ocul. Pharmacol. Ther. 17:517-527, 2001.

9. Kitaya, N., Yoshida, A., Ishiko, S., et al. Effect of timolol and UF021 (a prostaglandin-related compound) on pulsatile ocular blood flow in normal volunteers. Ophthalmic. Res. 29:139-144, 1997.

10. Georgopoulos, G.T., Diestelhorst, M., Fisher, R., et al. The short-term effect of latanoprost on intraocular pressure and pulsatile ocular blood flow. Acta. Ophthalmol. Scand. 80:54-58, 2002.

11. Geyer, O., Man, O., Weintraub, M., et al. Acute effect of latanoprost on pulsatile ocular blood flow in normal eyes. Am. J. Ophthalmol. 131:198-202, 2001.

12. Ishii, K., and Araie, M. Effect of topical latanoprost-timolol combined therapy on retinal blood flow and circulation of optic nerve head tissue in cynomolgus monkeys. Jpn. J. Ophthalmol. 44:227-234, 2000.
13. Ishii, K., Tomidokoro, A., Nagahara, M., et al. Effects of topical latanoprost on optic nerve head circulation in rabbits, monkeys, and humans. Invest. Ophthalmol. Vis. Sci. 42:2957-2963, 2001.

14. Liu, C.J., Ko, Y.C., Cheng, C.Y., et al. Effect of latanoprost $0.005 \%$ and brimonidine tartrate $0.2 \%$ on pulsatile ocular blood flow in normal tension glaucoma. Br. J. Ophthalmol. 86:1236-1239, 2002.

15. McKibbin, M., and Menage, M.J. The effect of once-daily latanoprost on intraocular pressure and pulsatile ocular blood flow in normal tension glaucoma. Eye 13:31-34, 1999.

16. Poinoosawmy, D., Indar, A., Bunce, C., et al. Effect of treatment by medicine or surgery on intraocular pressure and pulsatile ocular blood flow in normal-pressure glaucoma. Pressure and pulsatile ocular blood flow in normal-pressure glaucoma. Graefe's Arch. Clin. Exp. Ophthalmol. 240:721-726, 2002.

17. Sponsel, W.E., Mensah, J., Kiel, J.W., et al. Effects of latanoprost and timolol-XE on hydrodynamics in the normal eye. Am. J. Ophthalmol. 130:151-159, 2000.

18. Sponsel, W.E., Paris, G., Trigo, Y., et al. Latanoprost and brimonidine: Therapeutic and physiologic assessment before and after oral nonsteroidal anti-inflammatory therapy. Am. J. Ophthalmol. 133:11-18, 2002.

19. Tamaki, Y., Nagahara, M., Araie, M., et al. Topical latanoprost and optic nerve head and retinal circulation in humans. J. Ocul. Pharmacol. Ther. 17:403-411, 2001.

20. Vetrugno, M., Cantatore, F., Gigante, G., et al. Latanoprost $0.005 \%$ in POAG: Effects on IOP and ocular blood flow. Acta. Ophthalmol. Scand. 227(Suppl):40-41, 1998.

21. Akarsu, C., Bilgili, Y.K., Taner, P., et al. Short-term effect of latanoprost on ocular circulation in ocular hypertension. Clin. Exp. Ophthalmol. 32:373-377, 2004.

22. Inan, U.U., Ermis, S.S., Yucel, A., et al. The effects of latanoprost and brimonidine on blood-flow velocity of the retrobulbar vessels: A 3-month clinical trial. Acta. Ophthalmol. Scand. 81:155-160, 2003.

23. Januleviciene, I., Harris, A., Kagemann, L., et al. A comparison of the effects of dorzolamide/timolol-fixed combination versus latanoprost on intraocular pressure and pulsatile ocular blood flow in primary open-angle glaucoma patients. Acta. Ophthalmol. Scand. 82:730-737, 2004.

24. Kuba, G.B., Kurnatowski-Billion, M., Neuser, A.M., et al. Effect of latanoprost on ocular hemodynamics and contrast sensitivity. Ophthalmologe 98:535-540, 2001.

25. Nicolela, M.T., Buckley, A.R., Walman, B.E., et al. A comparative study of the effects of timolol and latanoprost on blood-flow velocity of the retrobulbar vessels. Am. J. Ophthalmol. 122:784-789, 1996.

26. Seong, G.J., Lee, H.K., and Hong, Y.J. Effects of $0.005 \%$ latanoprost on optic nerve head and peripapillary retinal blood flow. Ophthalmologica 213:355-359, 1999.

27. Stjernschantz, J., Selen, G., Astin, M., et al. Microvascular effects of selective prostaglandin analogues in the eye with special reference to latanoprost and glaucoma treatment. Prog. Retin. Eye Res. 19:459-496, 2000.

28. Nakajima, T., Matsugi, T., Goto, W., et al. New fluoroprostaglandin $\mathrm{F}$ (2alpha) derivatives with prostanoid FP-receptor agonistic activity as potent ocular-hypotensive agents. Biol. Pharm. Bull. 26:1691-1695, 2003.

29. Ota, T., Murata, H., Sugimoto, E., et al. Prostaglandin analogues and mouse intraocular pressure: Effects of tafluprost, latanoprost, travoprost, and unoprostone, considering 24-h variation. Invest. Ophthalmol. Vis. Sci. 46:20062011, 2005. 
30. Takagi, Y., Nakajima, T., Shimazaki, A., et al. Pharmacological characteristics of AFP-168 (tafluprost), a new prostanoid FP receptor agonist, as an ocular hypotensive drug. Exp. Eye Res. 78:767-776, 2004.

31. Ishida, N., Odani-kawabata, N., Shimazaki, A., et al. Prostanoids in the therapy of glaucoma. Cardiovasc. Drug Rev. 24:1-10, 2006.

32. Nagaoka, T., Sakamoto, T., Mori, F., et al. The effect of nitric oxide on retinal blood flow during hypoxia in cats. Invest. Ophthalmol. Vis. Sci. 43:3037-3044, 2002.

33. Sato, E., Sakamoto, T., Nagaoka, T., et al. Role of nitric oxide in regulation of retinal blood flow during hypercapnia in cats. Invest. Ophthalmol. Vis. Sci. 44:4947-4953, 2003.

34. Nagaoka, T., Mori, F., and Yoshida, A. Retinal artery response to acute systemic blood pressure increase during cold pressor test in humans. Invest. Ophthalmol. Vis. Sci. 43:1941-1945, 2002.

35. Yoshida, A., Ogasawara, H., Fujio, N., et al. Comparison of short- and long-term effects of betaxolol and timolol on human retinal circulation. Eye 12:848-853, 1998.

36. Yoshida, A., Feke, G.T., Mori, F., et al. Reproducibility and clinical application of a newly developed stabilized retinal laser Doppler instrument. Am. J. Ophthalmol. 135:356-361, 2003.

37. Feke, G.T., and Riva, C.E. Laser Doppler measurements of blood velocity in human retinal vessels. J. Opt. Soc. Am. 68:526-531, 1978 .

38. Feke, G.T., Goger, D.G., Tagawa, H., et al. Laser Doppler technique for absolute measurement of blood speed in retinal vessels. IEEE Trans. Biomed. Eng. 34:673-680, 1987.

39. Delori, F.C., Fitch, K.A., Feke, G.T., et al. Evaluation of micrometric and microdensitometric methods for measuring the width of retinal vessel images on fundus photographs. Graefe's Arch. Clin. Exp. Ophthalmol. 226:393-399, 1988.

40. Baker, M., and Wayland, H. On-line volume flow rate and velocity profile measurement for blood in microvessels. $\mathrm{Mi}$ crovasc. Res. 7:131-143, 1974.

41. Alm, A., and Bill, A. Ocular Circulation, 9th ed. St. Louis: Mosby, 1992.

42. Sjoquist, B., Johansson, A., and Stjernschantz, J. Pharmacokinetics of latanoprost in the cynomolgus monkey: 3rd com- munication: Tissue distribution after topical administration on the eye studied by whole-body autoradiography. Glaucoma Research Laboratories. Arzneimittelforschung 49:240-249, 1999.

43. Fujimori, K., Okada, T., and Urade, Y. Expression of $\mathrm{NADP}^{+}$-dependent 15-hydroxyprostaglandin dehydrogenase mRNA in monkey ocular tissues and characterization of its recombinant enzyme. J. Biochem. (Tokyo) 131:383-389, 2002.

44. Kaley, G., Hintze, T.H., Panzenbeck, M., et al. Role of prostaglandins in microcirculatory function. Adv. Prostagland. Thrombox. Leukot. Res. 13:27-35, 1985.

45. Ishikawa, H., Yoshitomi, T., Mashimo, K., et al. Pharmacological effects of latanoprost, prostaglandin E2, and F2alpha on isolated rabbit ciliary artery. Graefe's Arch. Clin. Exp. Ophthalmol. 240:120-125, 2002.

46. Kimura, T., Yoshida, Y., and Toda, N. Mechanisms of relaxation induced by prostaglandins in isolated canine uterine arteries. Am. J. Obstet. Gynecol. 167:1409-1416, 1992.

47. Zindel, G., Meistelman, C., and Gaudy, J.H. Effects of increasing enflurane concentrations on intraocular pressure. Br. J. Anaesth. 59:440-443, 1987.

48. Runciman, J.C., Bowen-Wright, R.M., Welsh, N.H., et al. Intraocular pressure changes during halothane and enflurance anaesthesia. Br. J. Anaesth. 50:371-374, 1978.

49. Studer, M.E., Martin, C.L., and Stiles, J. Effects of $0.005 \%$ latanoprost solution on intraocular pressure in healthy dogs and cats. Am. J. Vet. Res. 61:1220-1224, 2000.

Received: June 14, 2007 Accepted: March 20, 2008

Reprint Requests: Naohiro Izumi Department of Ophthalmology Asahikawa Medical College Midorigaoka-Higashi 2-1-1-1 Asahikawa 078-8510 Japan

E-mail: n_izumi@nifty.com 